\title{
PROCESSING AND PROPERTIES OF SUPERCONDUCTOR WIRES*
}

\author{
J. P. Singh, S. E. Dorris, M. T. Lanagan, K. C. Goretta, \\ U. Balachandran, and R. B. Poeppel $\quad \cdots \quad$ ANL/CP--73534 \\ Materials and Components Technology Division \\ Argonne National Laboratory \\ Argonne, IL 60439

\section{DISCLAIMER}

\begin{abstract}
This report was prepared as an account of work sponsored by an agency of the United States This report was prepared as an account of work sponsor any agency thereof, nor any of their Government. Neither the United States Government nor any agency thereal liability or responsiemployees, makes any warranty, express or implied, or assumes any legal liability or respons, bility for the accuracy, completeness, or usefulness of any information, apparatus, product, process disclosed, or represents that its use would not infringe privately owned rights. Reference herein to any specific commercial product, process, or service by trade name, trademark, manufacturer, or otherwise does not necessarily constitute or imply its endorser. The views mendation, or favoring by the United States Government or any agency thereor. The ve the and opinions of authors expressed herein do not United States Government or any agency thereof.
\end{abstract}

To be submitted for presentation at the Fourth International Symposium on Superconductivity. Tokyo, Japan, October 14-17, 1991.

*Work supported by the U.S. Department of Energy, Conservation and Renewable Energy, as a part of a DOE program to develop electric power technology, and Basic Energy Sciences-Materials Science, under Contract W-31-109-Eng-38. 
PROCESSING AND PROPERTIES OF SUPERCONDUCTOR WIRES*
J. P. Singh, S. E. Dorris, M. T. Lanagan. C.-T. Wu, K. C. Goretta, J. Joo,
U. Balachandran, and R. B. Poeppel

Materials and Components Technology Division. Argonne NationalLaboratory Argonne, IL 60439 USA

\section{ABSTRACT}

Variables in fabrication of superconductor wires by extrusion and by powder-in-tube processing are discussed. Decomposition of plastically extruded $\mathrm{YBCO}$ is minimized by firing at reduced total pressure. Extruded wires of YBCO were densified with fine-grained microstructures by sintering at an oxygen partial pressure of $10^{-3} \mathrm{MPa}$. A reduction in average grain size from 23 to $4 \mu \mathrm{m}$ increased strength from 83 to $191 \mathrm{MPa}$. Addition of 15 vol.\% Ag particles further increased the strength to $220 \mathrm{MPa}$, with the increase resulting from compressive stresses in YBCO matrix due to the Ag. In powder-in-tube processing, primary considerations are the mechanicalworking and heating schedules. The best properties in Ag-clad Bi-based superconductors were obtained with many small reductions during working and by use of liquid-phase formation during sintering to promote grain growth.

KEY WORDS: YBCO/BSCCO superconductors, extrusion, powder-in -tube processing, oxygen partial pressure, strength 


\section{INTRODUCTION}

The high critical temperatures of ceramic superconductors allow the use of much simpler cryogenic systems and relatively inexpensive liquid nitrogen, suggesting the possibility that ceramic superconductors might one day be widely useful and provide large-scale energy conservation. Large-scale applications will require tulk fabrication processes by which long lengths of continuous superconductor can be produced at faster rates. To this end. considerable effort has been devoted to the fabrication of superconducing wires by extrusion process [1]. Important considerations in fabrication of wire by plastic extrusion include control of atmosphere during removal of organic constituents and optimization of mechanical properties by control of microstructure and addition of second phases. Long lengths of wire with high strength have been fabricated, but their capacity to carry large currents has been limited [1]. Therefore, an alternative route of wire fabrication by powder-in-tube processing has been also investigated [2] for achieving large critical current densities. In powder-in-tube processing, the primary consideration is the mechanical-working and heat-treatment schedule. In the present paper we will describe the parameters that are important for the extrusion of $\mathrm{YBa}_{2} \mathrm{Cu}_{3} \mathrm{O}_{\mathrm{x}}$ (YBCO) wire and processing of $\mathrm{BiSrCaCuO}$ (BSCCO) wire by the powder-in-tube technique. The BSCCO powders used were both with and without lead $(\mathrm{Pb})$ dopings. The effects of these processing parameters on the microstructures and the resulting properties will be discussed. 


\section{EXPERIMENT}

Powder if YBCO is made by solid-state reaction of the constituent oxides. The appropriate proportions of $\mathrm{Y}_{2} \mathrm{O}_{3}, \mathrm{BaCO}_{3}$, and $\mathrm{CuO}$ are mixed and milled in methanol for $\approx 12 \mathrm{~h}$. After drying, the mixtures are calcined in flowing oxygen at a reduced total pressure of $\approx 2 \mathrm{~mm} \mathrm{Hg}$. This method [3] leads to decomposition of $\mathrm{BaCO}_{3}$ at lower temperatures, avoids the formation of impurity phases, and, in the case of YBCO, produces phase-pure material after a single calcination at $800^{\circ} \mathrm{C}$ [3]. The $\mathrm{Bi}_{1.8} \mathrm{~Pb}_{0.4} \mathrm{Sr}_{2} \mathrm{Ca}_{2.2} \mathrm{Cu}_{3} \mathrm{O}_{\mathbf{X}}(2223$ $\mathrm{BSCCO}$ ) powder was made by solid state reaction of the constituent oxides. The appropriate amounts of $\mathrm{Bi}_{2} \mathrm{O}_{3}, \mathrm{PbO}, \mathrm{SrCO}_{3}, \mathrm{CaCO}_{3}$, and $\mathrm{CuO}$ are mixed and milled for $\approx 12 \mathrm{~h}$ in isopropyl alcohol using alumina media. The milled slurry is dried and subsequently calcined. The calcination process involves two steps. First, the powder mixture is slowly heated to $\approx 700^{\circ} \mathrm{C}$ for $6 \mathrm{~h}$ in flowing oxygen at a reduced total pressure of $\approx 5 \mathrm{~mm} \mathrm{Hg}$. Subsequently, the atmosphere is changed to ambient air and the temperature is raised to $860^{\circ} \mathrm{C}$. The powder is held at the temperature for $100 \mathrm{~h}$. The $2212 \mathrm{BSCCO}$ powder was made by a similar process, the details of which san be found in Ref 4.

For the extrusion of wires, YBCO powder is mixed with appropriate solvent, dispersant, binder, and plasticizer to formulate a slip to be easily formed into various shapes while retaining satisfactory strength in the green state [1]. The solvent provides a fluid medium for the powder and the other additives. Because water is known to attack the YBCO superconductor by preferentially dissolving $\mathrm{Ba}$, organic solvents such as methyl ethyl ketone and xylene are used. In many cases, after the superconductor slip is 
prepared, silver flakes (mean particle size $\approx 15 \mu \mathrm{m}$ ) are added to make a YBCO/Ag composite ( 85 vol.\% YBCO/15 vol.\% silver). This leads to improved mechanical properties in the superconductor [5], as will be described later. $\mathrm{ZrO}_{2}$ milling media are then added, and the formulation is vibratory-milled for $\approx 16 \mathrm{~h}$. Milling reduces the particle size of the YBCO powder, making it more sinterable and more likely to produce a high-density superconductor.

After milling the above formulation, some solvent is allowed to evaporate. This yields a plastic mass that is forced through a die at high pressure to produce a YBCO/Ag superconducting wire. Superconductor wires have been extruded at Argonne National Laboratory (ANL) with diameters between 0.1 and $3.0 \mathrm{~mm}$ and lengths up to $20 \mathrm{~m}$. In the green state (i.e., before firing), extruded wires exhibit great flexibility and can be easily formed into coils. Details of the firing schedules for these wires can be found in Refs 1 and 6 .

The heat treatment of wire includes several steps. First, the wire is fired in flowing oxygen $\left(\approx 1160 \mathrm{~cm}^{3} / \mathrm{min}\right)$ at a reduced total pressure $(\approx 7.6 \mathrm{~mm} \mathrm{Hg})$ to facilitate removal of gaseous species formed during decomposition of organic additives and prevent their reaction with the superconductor. The temperature is slowly increased to $\approx 260^{\circ} \mathrm{C}$ at a rate of $0.1{ }^{\circ} \mathrm{C} / \mathrm{min}$. The wire specimen is held at this temperature for $10 \mathrm{~h}$. After the organics are removed at $260^{\circ} \mathrm{C}$, the temperature is raised to sintering temperature at a rate of $1^{\circ} \mathrm{C} / \mathrm{min}$. The specimens are sintered at different temperatures, oxygen partial pressures, and for different lengths of time to obtain various microstructures. After sintering, the specimens were annealed at $450^{\circ} \mathrm{C}$ for $12 \mathrm{~h}$ in flowing oxygen atmosphere at a total pressure of $760 \mathrm{~mm} \mathrm{Hg}$. 
For powder-in-tube processing, superconducting powder (BSCCO 2223 or 2212) were loaded in a silver tube $(6.35-\mathrm{mm}$ outer diameter, $4.35-\mathrm{mm}$ inner diameter) and the assemblies were compacted by swaging, drawing, or rolling. The Ag sheath provides a barrier that protects the superconductor from damage and environmental degradation. The reactivity of high- $\mathrm{T}_{\mathrm{C}}$ superconductors with moisture is well documented [7].

In some of the experiments, each of the $\mathrm{BSCCO} / \mathrm{Ag}$ tubes was swaged into wires $1.1-1.3 \mathrm{~mm}$ in diameter. These wires were used to fabricate the multifilament wires. The swaged 2212 and 2223 wires, which each contained a single oxide filament, were sintered at $840^{\circ} \mathrm{C}$ in air for $50 \mathrm{~h}$. After this treatment designed to induce grain growth, the wires were subjected to a combination of flat rolling and sintering. In the first rolling step, seven pieces of each single-filament wire were cut, packed into a 6.35 $\mathrm{mm} \mathrm{Ag}$ tube, swaged to $5.15 \mathrm{~mm}$, and rolled into tape of $1.44 \mathrm{~mm}$ total thickness. A second sintering, identical to the first one, was then performed. An additional rolling operation decreased each tape thickness to $0.72 \mathrm{~mm}$. Final sintering occurred at $840^{\circ} \mathrm{C}$ for $30 \mathrm{~h}$.

For the monofilaments of $2212 / \mathrm{Ag}$, wires were cold rolled into tapes. The flattened tapes were heated in air at $890^{\circ} \mathrm{C}$ for $0.5 \mathrm{~h}$, and were then cooled to $870^{\circ} \mathrm{C}$ and held for $10 \mathrm{~h}$. Final rolling produced a tape $0.12 \mathrm{~mm}$ thick. The final heat treatment in air was conducted at $\approx 840^{\circ} \mathrm{C}$ for $100 \mathrm{~h}$.

The phase composition of the powders was confi med by X-ray diffraction and differential thermal analysis (DTA). The critical temperature and current density were measured by four-probe resistivity. Critical current 
density $\left(J_{c}\right)$ was measured at 4.2 and $77 \mathrm{~K}$ : a $1 \mu \mathrm{V} / \mathrm{cm}$ criterion was used. Strength of the YBCO wires was measured in a three-point bending mode with a support span of $1.825 \mathrm{~cm}$ and the cross-head speed of 0.127 $\mathrm{cm} / \mathrm{min}$.

\section{RESULTS AND DISCUSSION}

Wires produced by extrusion contain $\approx 10 \mathrm{wt} . \%$ organics in the green state, which must be completely removed without damaging the superconductor. Incomplete removal of organics can cause decomposition of the superconductor or leave carbon-rich material at the grain boundaries, either of which will degrade superconducting properties. Organics can be removed easily by thermal decomposition in the temperature range of 240$350^{\circ} \mathrm{C}$, but if the decomposition proceeds too rapidly, wires can bloat severely and in some cases even explode. In the firing of any ceramic, it is important to control the rate at which organics are removed, but it is especially important in firing YBCO, because YBCO decomposes in the presence of $\mathrm{CO}_{2}$ and $\mathrm{H}_{2} \mathrm{O}$ [8], two products that are formed during decomposition of organics.

When extruded $\mathrm{YBCO}$ is fired at reduced total pressure, the concentrations of $\mathrm{CO}_{2}, \mathrm{CO}$, and $\mathrm{H}_{2} \mathrm{O}$ are minimized, and decomposition of $\mathrm{YBCO}$ is greatly minimized or completely avoided. But when firing is done at ambient pressure, the harmful gaseous products accumulate and lead to gross decomposition of YBCO. This was demonstrated in the following experiment: YBCO powder was mixed with the organics that are used in extrusion, then the mixture was fired in flowing oxygen at either ambient or 
reduced pressure $(\approx 2$ torr) . Two different powders were used: some produced by solid-state reaction at reduced pressure, and some produced by a liquid mix technique. Figures 1 and 2 show the schematic X-ray patterns of samples that were taken from the mixtures at temperatures of 240,300 , and $350^{\circ} \mathrm{C}$. Figure 1 shows that, when the YBCO/organic mixtures were fired at ambient pressure, both samples of YBCO decomposed (the liquid-mix powder at $240^{\circ} \mathrm{C}$ and the solid-state powder at $300^{\circ} \mathrm{C}$ ). On the other hand, Figure 2 shows that YBCO did not decompose when fired at reduced total pressure.

The YBCO wires sintered at various temperatures in flowing oxygen at $\mathrm{pO}_{2}=$ $0.1 \mathrm{MPa}$ ranged in density from 79 to $98 \%$ theoretical, as shown in Table I. As expected, density increases with increasing sintering temperature and time. As shown in Table I, average grain size, i.e., length, increases from $\approx 4$ $\mu \mathrm{m}$ for specimens sintered at $910^{\circ} \mathrm{C}$ for $10 \mathrm{~h}$ to $23 \mu \mathrm{m}$ for specimens sintered at $950^{\circ} \mathrm{C}$ for $20 \mathrm{~h}$. In addition, the largest grain size also increased with increasing sintering time and temperature. It can be seen in Table I that largest grain size increases from $\approx 5 \mu \mathrm{m}$ for specimens sintered at $910^{\circ} \mathrm{C} / 10 \mathrm{~h}$ to $\approx 150 \mu \mathrm{m}$ for specimens sintered at $950^{\circ} \mathrm{C} / 20 \mathrm{~h}$. Although, grain size increased with increasing sintering temperature, the increase was minimal for specimens sintered at temperature above $935^{\circ} \mathrm{C}$ due probably to large grains impinging on each other. The specimens sintered at $910^{\circ} \mathrm{C}$ $\left(\mathrm{pO}_{2}=0.1 \mathrm{MPa}\right)$ had a very low density of $79 \%$ theoretical.

To obtain small grain microstructures, the specimens need to be sintered at relatively low temperatures. However, as discussed above, sintering at lower temperatures $\left(\approx 910^{\circ} \mathrm{C}\right)$ and $\mathrm{pO}_{2}=0.1 \mathrm{MPa}$ resulted in a relatively low density 
Table I. Density. Grain Size, and Strength of YBCO Wires Sintered at Various $\mathrm{pO}_{2}$ with Different Heat Treatment.

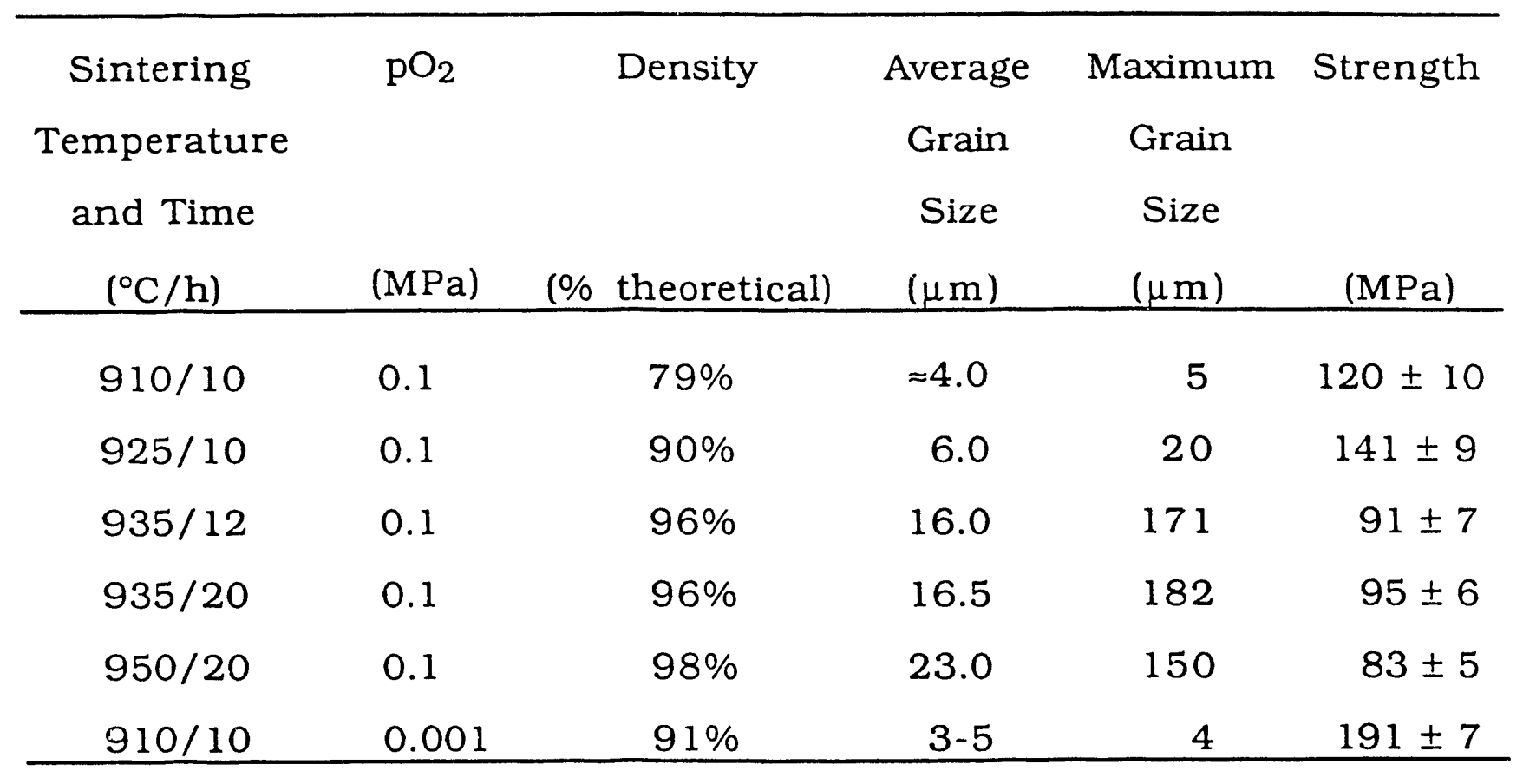

of $79 \%$ theoretical. Such a low density is undesirable from the standpoint of both superconducting and mechanical properties. Therefore, to achieve high density at a relatvely low temperature $\left(910^{\circ} \mathrm{C}\right)$, the specimens were sintered at a low oxygen partial pressure $\left(\mathrm{pO}_{2}=0.001 \mathrm{MPa}\right)[9]$. A density of $91 \%$ theoretical and a fine microstructure with an average grain size of $\approx 4$ $\mu \mathrm{m}$ was obtained at $\mathrm{pO}_{2}=0.001 \mathrm{MPa}$. We is believe that the increase in density with a decrease in $\mathrm{pO}_{2}$ is the result of enhanced sintering kinetics probably caused by both an increase in defect concentration and a decrease in activation energy of the rate-controlling species [10]. It can be seen in Table 1 that the strength shows an inverse dependence on grain size for specimens with density over 90\% theoretical. The strength increased from 83 to $191 \mathrm{MPa}$ when the average grain size decreased from 23 to $4 \mu \mathrm{m}$. 
Some of the YBCO wires with 15 vol. \% Ag addition were also sintered at $890^{\circ} \mathrm{C}$ for $10 \mathrm{~h}$ to obtain a density of $91 \%$ with an average grain size of $4 \mu \mathrm{m}$. These specimens had a strength value of $220 \mathrm{MPa}$. For the same density and grain size, this represents an increase in strenth of YBCO specimens from 191 to $220 \mathrm{MPa}$ as a result of 15 vol.\% Ag addition. It is believed that the Ag particles induce compressive stress in the YBCO matrix [11] and pin the propagating crack resulting in strength improvement. The critical current densities of YBCO/Ag wires was typically $400-600 \mathrm{~A} / \mathrm{cm}^{2}$ and has ranged as high as $2800 \mathrm{~A} / \mathrm{cm}^{2}$. In every case, $\mathrm{J}_{\mathrm{c}}$ drops dramatically with applied magnetic field (A field of $50 \mathrm{G}$ results in $\approx 50 \%$ decrease in the zero field $J_{C}$.), indicating that the YBCO superconductors are controlled by weak links.

An alternative approach that produces superior superconducting properties is powder-in-tube processing of the BSCCO superconductors. For multifilament 2212/Ag and 2223/Ag wires, earlier efforts [Ref. 12] focused on swaging and rolling, with use of intermediate heat treatments to promote grain growth. Mulifilament wires with transport $\mathrm{J}_{\mathrm{C}}$ values at $4.2 \mathrm{~K}$ greater than $3.5 \times 10^{4} \mathrm{~A} / \mathrm{cm}^{2}$ were produced. The $\mathrm{J}_{\mathrm{c}}$ values at $77 \mathrm{~K}$ were only $\approx 10^{3} \mathrm{~A} / \mathrm{cm}^{2}$.

The current efforts in 2212 / Ag wires have incorporated many changes in the processing sequence. First, drawing is now used; the reductions per pass are generally $10-15 \%$. Second, only two heat treatments are employed. Third, after the first rolling, the heat treatment induces significant partial melting. The first heat treatment yields relatively large grains that exhibit significant texture. The final heat treatment improves the texture 
substantially (Fig. 3). It is noted that several intermediate heat treatment schedules have been attempted. Only those that induced appreciable melting have produced highly aligned microstructures and good superconducting properties.

The $J_{c}$ values of these newer tapes have only been measured at $4.2 \mathrm{~K}$ in zero applied magnetic field, and only short sections have been tested. Measurements in field and at higher temperatures are planned. The transport $\mathrm{J}_{\mathrm{c}}$ was $7.3 \times 10^{3} \mathrm{~A} / \mathrm{cm}^{2}$ after the first heat treatment and $1.0 \times 10^{5}$ $\mathrm{A} / \mathrm{cm}^{2}$ after the final heat treatment. The critical current of the final tape was $83 \mathrm{~A}$. It is clear that the increase in $\mathrm{J}_{\mathrm{c}}$ is related to the improved texture of the final product.

The $\mathrm{J}_{\mathrm{c}}$ achieved is probably sufficient for low-temperature applications such as high-field magnets. Toward that end, coils are now being wound from the 2212/Ag tapes. A concern for these coils is mechanical reliability. The 2212/Ag tapes have to date been susceptible to mechanical damage and thermal shock. For example, when the tape that carried 83 A was warmed to room temperature and the current leads were disconnected and reconnected, the critical current at $4.2 \mathrm{~K}$ was reduced to $45 \mathrm{~A}$. Efforts to improve the reliability of these tapes are underway. Alloying of the core is the method that appears to offer the most promise. In addition, the possible problems associated with the BSCCO/Ag interface are under study. 


\title{
SUMMARY
}

Continuous YBCO wires were produced by plastic extrusion. The strength and reliability of these wires have been improved substantially by control of the heat-treatment atmosphere and by addition of metallic Ag. BSCCO wires were produced in $\mathrm{Ag}$ tubes. $\mathrm{J}_{\mathrm{c}}$ values at $4.2 \mathrm{~K}$ have reached $10^{5} \mathrm{~A} / \mathrm{cm}^{2}$. However, the mechanical properties of these wires have yet to be optimized.

\section{ACKNOWLEDGMENTS}

\author{
L \\ WWork supported by the U.S. Department of Energy (DOE), Office of Utility \\ Technologies, Conservation and Renewable Energy, as a part of a DOE program to \\ develop electric power technology (JPS, SED, MTL, KCG, UB, RBP), under \\ Contract W-31-109-Eng-38; and by the National Science Foundation, Office of \\ Science and Technology Centers (CTW, JJ), under Contract STC-8809854.
}

\section{REFERENCES}

1. Dorris S, Dusek JT, Lanagan MT, Picciolo JJ, Singh JP, Creech JE, Poeppel RB (1991) Ceram. Bull. 70: 722

2. Balachandran U, Poeppel RB, Emerson JE, Johnson SA, Lanagan MT, Youngdahl CA, Shi D, Goretta KC, Eror NG (1989) Mater. Lett. 8: 454

3. Powder in Tube

4. Karbarz FA, Lacy OD, Goretta KC, Balachandran U, Shi D, Chen JG, Xu M, Hash MC (1990) Mater. Res. Bull. 25: 759

5. Singh JP, Leu HJ, Poeppel RB, Van Voorhees E, Goudey GT, Winsley K, Shi D (1989) J. Appl. Phys. 66: 3154 
6. Lanagan MT, Poeppel RB. Singh JP, Dos Santos DI, Degener JK, Dusek JT, Goretta KC (1989) J. Less-Common Met. 149: 305

7. Bansal NP, Sandkuhl AL (1988) Appl. Phys. Lett. 52: 323

8. Gao Y, Merkle KL, Zhang C, Balachandran U, Poeppel RB (1990) J. Mater. Res. 5: 1363

9. Singh JP, Guttschow RA, Kupperman DS, Dusek JT, Poeppel RB In: Proc. Third Symp. on High-Temperature Superconductors: Processing aild Microstructure Property Relationsips, 1991 TMS Meeting and Expositicn, New Orleans, LA, USA, February 17-21, 1991 (in press)

10. Chen N, Shi D, Goretta KC (1989) J. Appl. Phys. 66: 2485

11. Kupperman DS, Singh JP, Faber Jr. J, Hitterman RL (1989) J. Appl. Phys. 66: 3396

12. Wu C-T, Goretta KC, Shi D, Poeppel RB In: Whang SH, DasGupta A. Laibowitz RB (eds) High Temperature Superconducting Compounds III, The Metallurgical Society, Warrendale, PA, USA, (in press) 

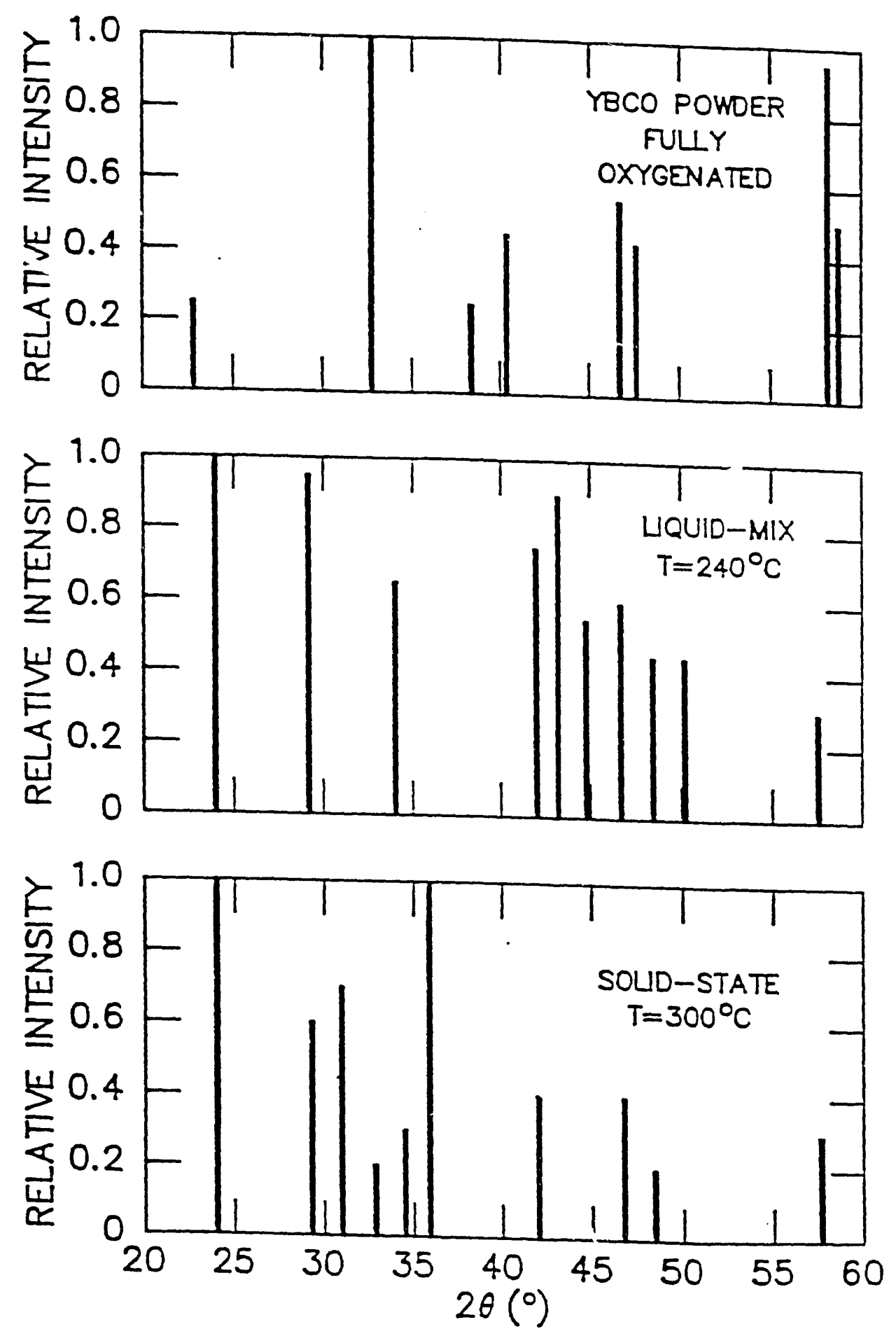

Fig. I Schematic X-ray patterns of fully oxygenated YBCO powder and two other YBCO powders fired at ambient pressure in contact with organics used inextrusion. Both powders fired wirh organics decomposed during firing. 

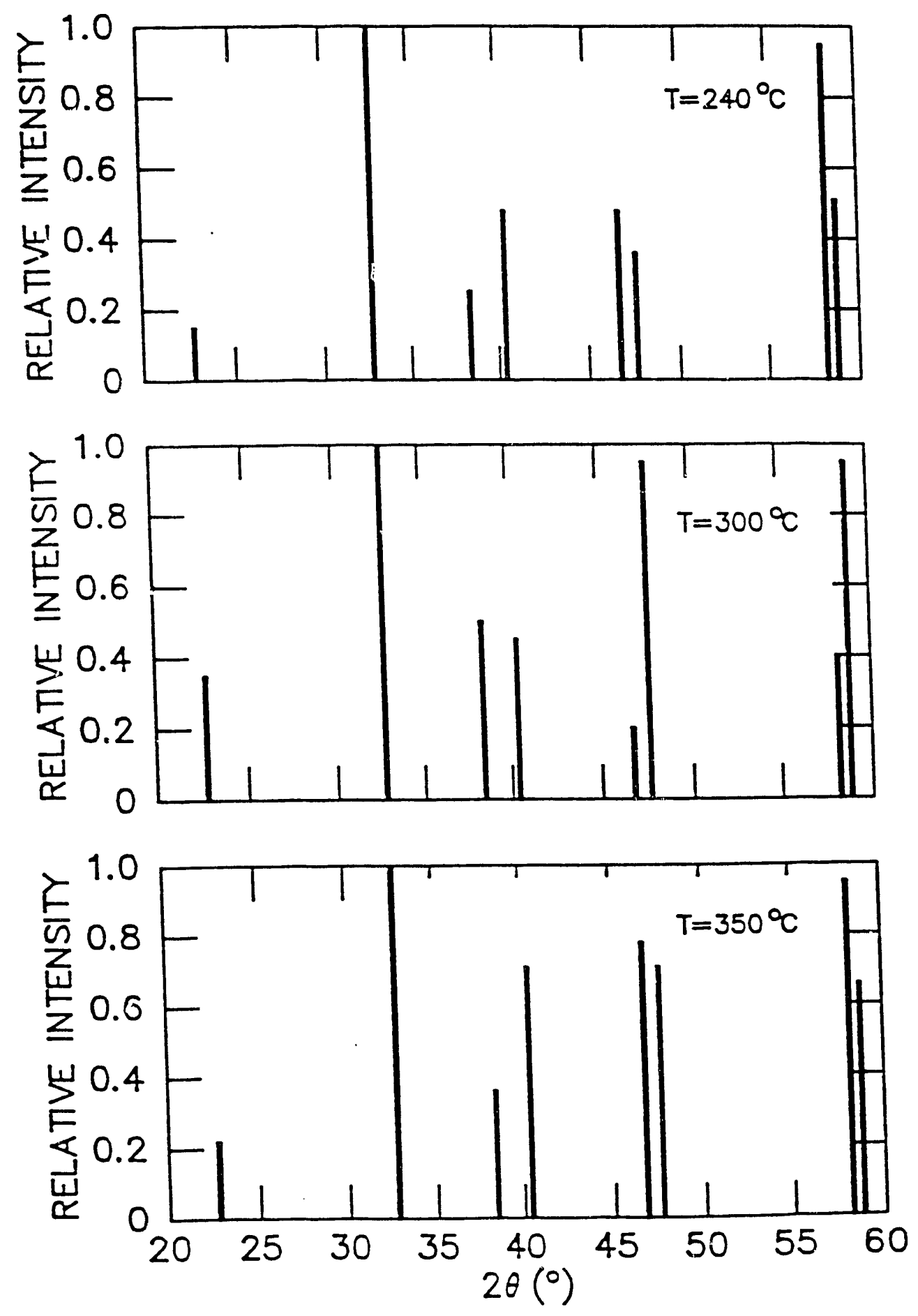

Fig. 2 Schematic X-ray patterns of YBCO powder as a function of temperature. The powder was fired at reduced total pressure in contact with organics used in extrusion and showed no sign of decomposition. 
(a)
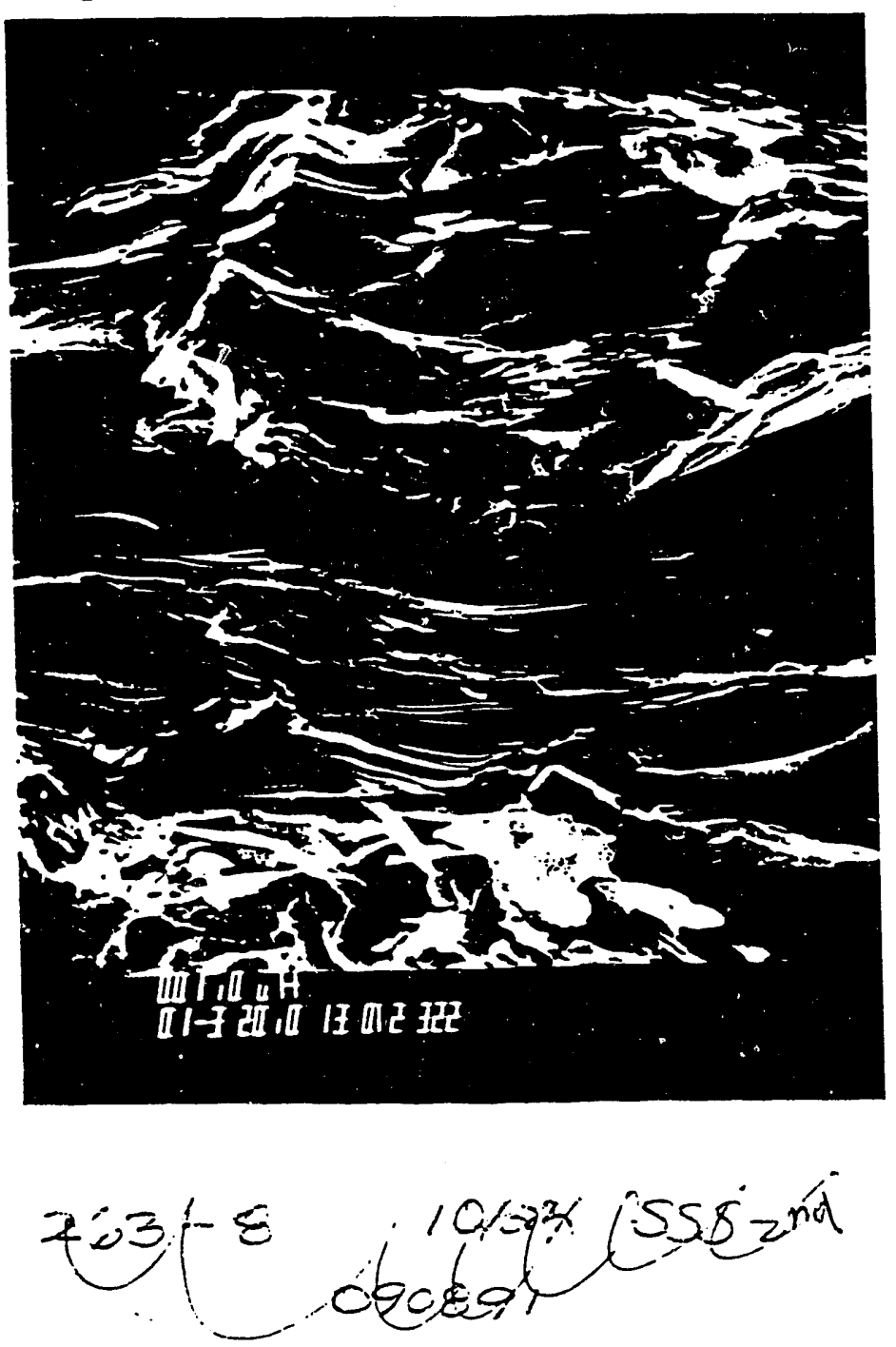

(b)
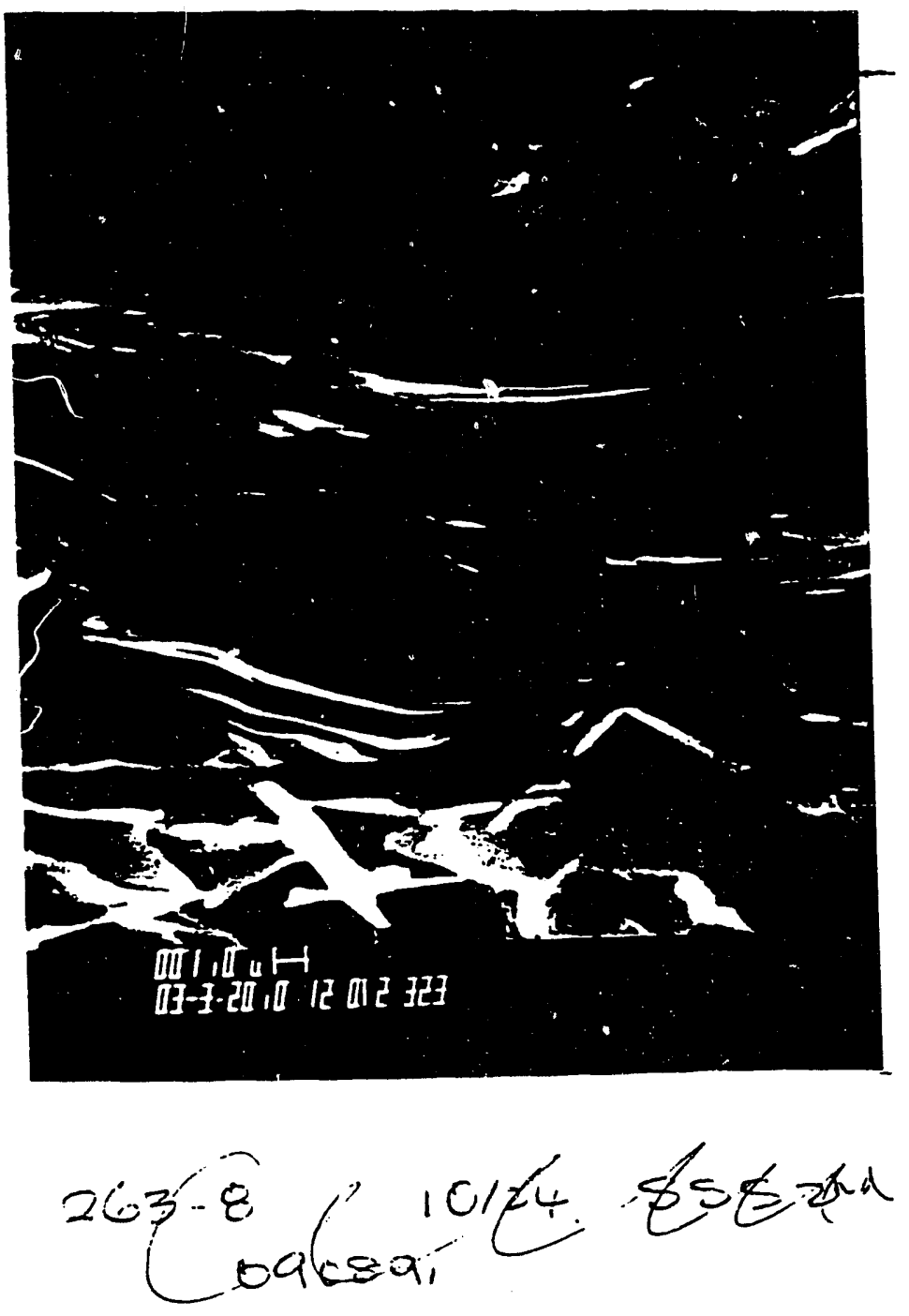

Fig. 3 Scanning Electron Micrographs of transverse cross sections of 2212 BSCCO/Ag tapes: (a) after first rolling and heat treatment at $890^{\circ} \mathrm{C}$ and (b) after a second rolling and heat treatment at $837^{\circ} \mathrm{Ce}^{\circ}$ for $10 \mathrm{c}^{\mathrm{h}} \mathrm{h}$ 

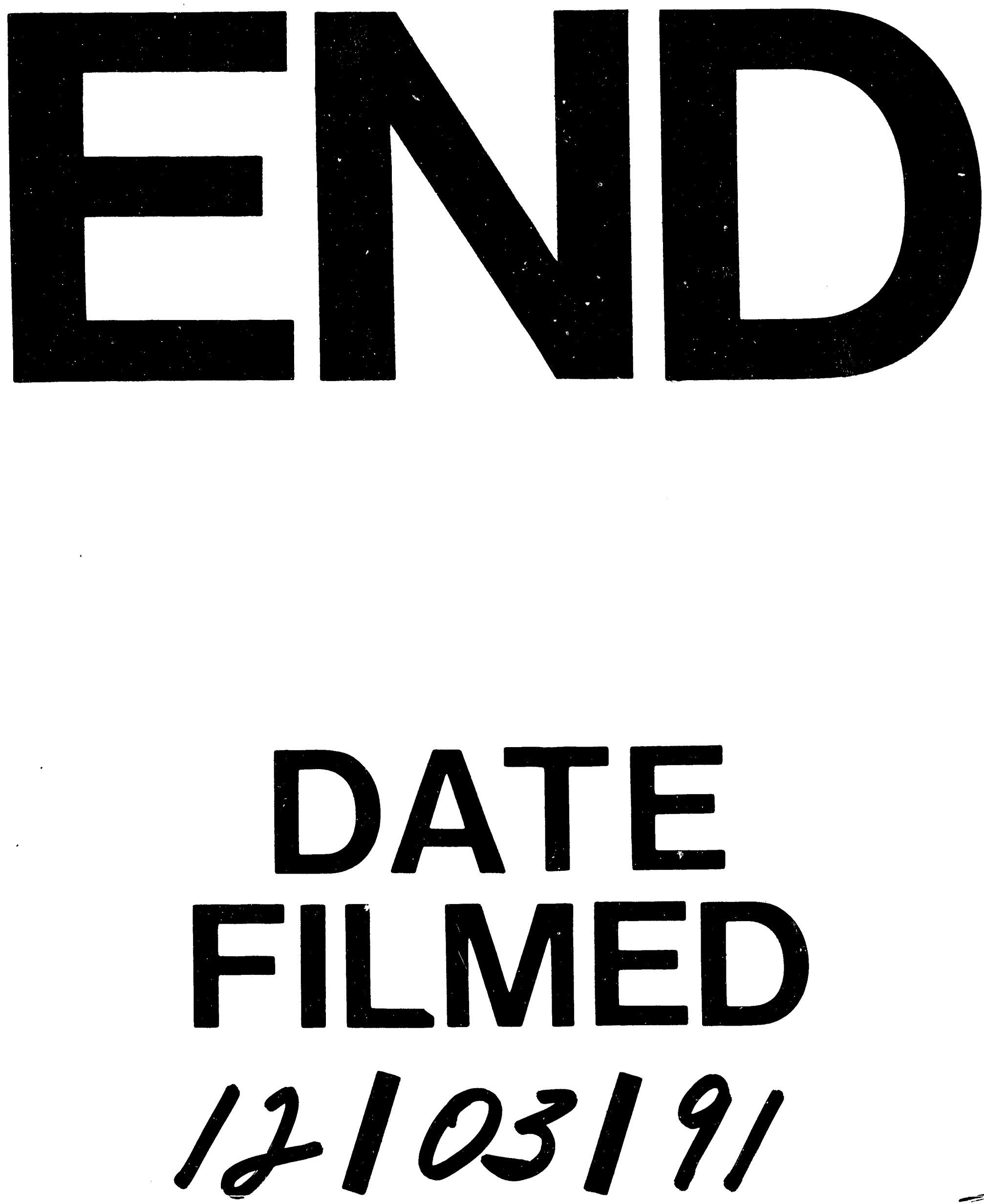

$I$

$=$ 
